\title{
Chain reaction
}

\author{
When a natural disaster strikes civilization it often does so in numerous ways, with unforeseen \\ consequences, as evidenced by recent events in Japan.
}

When the sea floor around $130 \mathrm{~km}$ off the coast of Sendai ruptured on 11 March, the largest recorded earthquake in Japanese history ensued. The $M 9$ quake triggered a catastrophic tsunami. The two-pronged attack destroyed regular and back-up power supplies to the Fukushima nuclear power plant, and set in motion a partial nuclear meltdown. The tragic chain of events highlights the manifold and unforeseen consequences of natural disasters; a fact that should not be forgotten in the present nuclear renaissance.

Japan lies along an active subduction zone, and is therefore one of the most disaster-prone, and -prepared, regions in the world. However, although the shake-resistant buildings fared well in the earthquake, the tsunami defences and evacuation drills proved no match for the incoming waters, which wiped away entire villages along the northeastern coast of Japan (Nature 471, 556-557; 2011). The disaster killed more than 20,000 people, and left the country in a state of chaos.

The scramble for food, clean water and energy in the northeast of the country has been accompanied by intense efforts to limit further damage at the Fukushima Daiichi nuclear power plant. The earthquake destroyed electricity supplies at the plant, and the tsunami wiped out the emergency power supply - diesel generators that powered the cooling system. Heat built up, leading to a series of explosions, fires and leaks. Significant amounts of radioactive material were discharged into the atmosphere and ocean as a result, and continue to seep into the environment at the time of writing.

The magnitude and fate of the contaminants released is uncertain. But potentially dangerous levels of radiation have been observed $30-40 \mathrm{~km}$ away, to the northwest of the plant, and the long-lived radioisotope caesium-137 — which has a half-life of $30 \mathrm{yr}$ - has been detected 25-28 km away (Nature 472, 7; 2011).

It is hoped that some of the more extreme impacts on human health have been avoided through the establishment of a $20-\mathrm{km}$ exclusion zone and the distribution of potassium iodide tablets. But the risks associated with long-term exposure to the

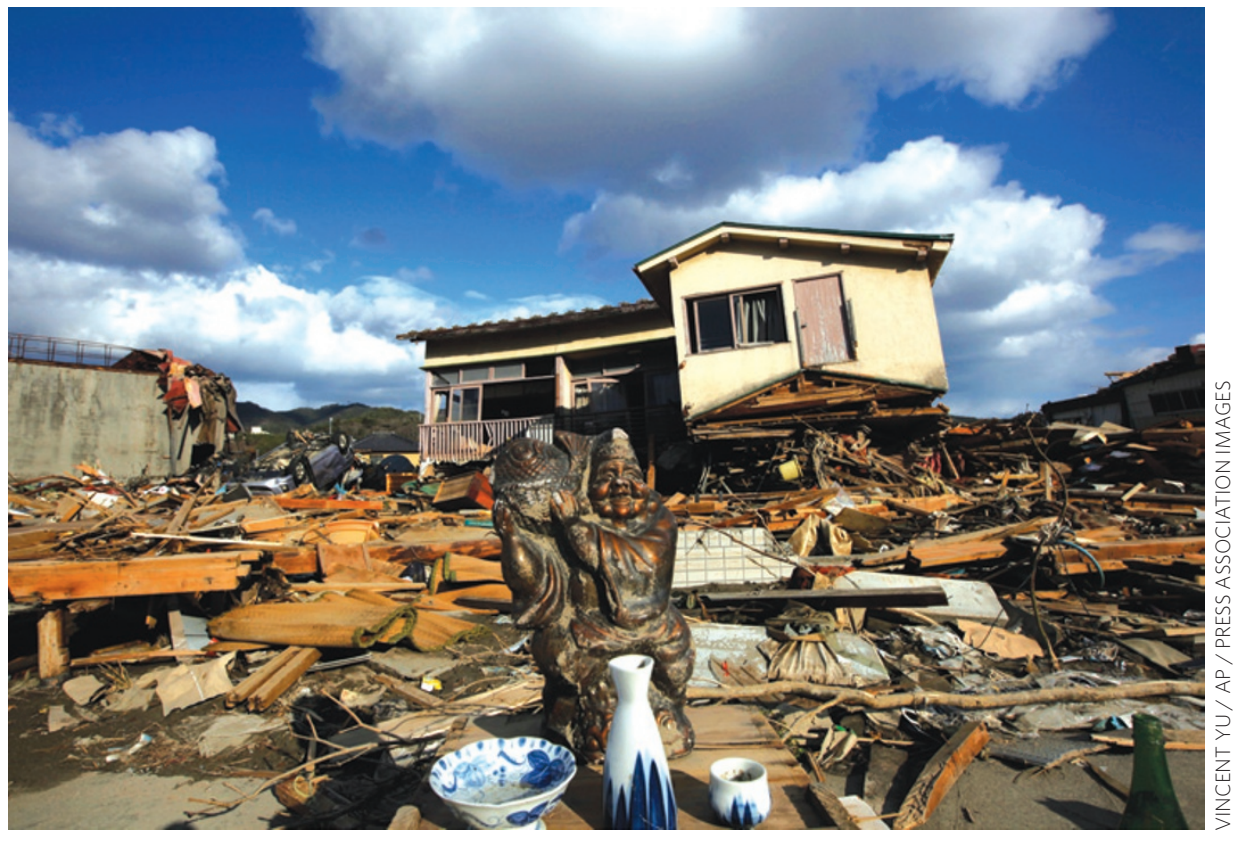

low levels of radiation that may have affected a larger portion of the population remain unclear (Nature doi:10.1038/news.2011.206; 2011). This uncertainty, in turn, could breed less tractable problems. According to the UN Chernobyl Forum Report, the impact of the 1986 disaster on mental health was the "largest public-health problem caused by the accident to date" (Nature 472, 7; 2011). The despondency and fatalism of those exposed to the radiation is thought to have led to increased levels of drinking and smoking in Belarus and Ukraine, which of course carry their own health risks.

Unsurprisingly, concerns about the risks associated with nuclear power have risen following the Fukushima disaster. Countries around the world are re-assessing the safety of their nuclear facilities (Science 331, 1502-1503; 2011). Germany has even shut down a number of older plants. And Germany, Switzerland and China have halted plans to build new plants; the Indian government is under pressure from its scientists to do the same.

At the same time, nuclear experts have been keen to point out that modern power plants are equipped with more sophisticated safety features and numerous layers of defence, unlike the older designs on which the
Fukushima plant is based (Science 331, 1506; 2011; Nature doi:10.1038/news.2011.209; 2011). Indeed, it has been suggested than many of the events at Fukushima would never have arisen had the new generation of nuclear plants been in place.

It is certainly reassuring to know that reactor designs have improved and that some of the accidents in the past few weeks could be avoided in the future. But in the midst of these reassurances, it should not be forgotten that nuclear facilities cannot dispense with human intervention altogether in the wake of an emergency (Nature 471, 549; 2011), and that it is precisely this intervention, and the ability and willingness of workers to put themselves at risk, that seems to have prevented fullscale nuclear meltdown at Fukushima. are multifaceted - hurricane-strength winds can be accompanied by storm surges, storms by torrential rains and floods, and earthquakes by tsunamis. Add in the everpresent threat of terrorist attacks and the projected increases in climate extremes, and it seems unwise to place too much faith in the resilience of the new generation of power plants, which ultimately still rely on the most fragile of factors - human intervention.
Natural disasters by their very nature 